\title{
Estimation Of Direct Medical Costs Of Middle East Respiratory Syndrome Coronavirus Infection: A Single-Center Retrospective Chart Review Study
}

This article was published in the following Dove Press journal: Infection and Drug Resistance

\author{
Yazed AIRuthia (1) ${ }^{1,2}$ \\ Ali M Somily $\mathbb{D}^{3}$ \\ Amal S Alkhamali' \\ Ohud H Bahari $\mathbb{D}^{\prime}$ \\ Raneem J AlJuhani' \\ Mohammad Alsenaidy (D) ${ }^{4}$ \\ Bander Balkhi (D) ${ }^{1,2}$ \\ 'Department of Clinical Pharmacy, \\ College of Pharmacy, King Saud \\ University, Riyadh, Saudi Arabia; \\ ${ }^{2}$ Pharmacoeconomics Research Unit, \\ College of Pharmacy, King Saud \\ University, Riyadh, Saudi Arabia; \\ ${ }^{3}$ Microbiology Department, College of \\ Medicine, King Saud University, Riyadh, \\ Saudi Arabia; ${ }^{4}$ Department of \\ Pharmaceutics, College of Pharmacy, King \\ Saud University, Riyadh, Saudi Arabia
}

Correspondence: Yazed AIRuthia Department of Clinical Pharmacy, College of Pharmacy, King Saud University, Riyadh, Saudi Arabia

Tel +996 | $\mid 4677483$

Fax +966 II 4677480

Email yazeed@ksu.edu.sa
Background: Among the countries affected by Middle East respiratory syndrome (MERS), Saudi Arabia was impacted the most, with 2,058 cases reported as of June 2019. However, the impact of the MERS epidemic on the Saudi economy is unknown.

Purpose: The present study aimed to evaluate the direct medical costs associated with the management of MERS cases at a tertiary referral hospital in Riyadh, Saudi Arabia.

Methods: The study involved a retrospective chart review of confirmed cases of MERS coronavirus (MERS-CoV) infections in a tertiary care referral center in Riyadh, Saudi Arabia, from January 2015 to October 2018. The collected data included sociodemographic characteristics, medical information, and the cost of hospitalization of each patient as estimated by micro-costing.

Results: A complete set of relevant information was available only for 24 of 44 identified MERS-CoV cases. Patients were mostly females, and the mean age was 52 years. Diabetes, hypertension, and chronic kidney disease were the most frequent comorbidities. The length of hospital stay varied from 1 to 31 days, averaging $4.96 \pm 7.29$ days. Two of the 24 patients died. The total cost of managing a MERS case at the hospital ranged from $\$ 1278.41$ to $\$ 75,987.95$ with a mean cost of $\$ 12,947.03 \pm \$ 19,923.14$.

Conclusion: The findings of this study highlight the enormous expenses incurred by the Saudi health care system due to the MERS-CoV outbreak and the importance of developing an enforceable nationwide policy to control MERS-CoV transmission and infection.

Keywords: Middle East respiratory syndrome coronavirus, costs and cost analysis, Saudi Arabia

\section{Introduction}

Middle East respiratory syndrome coronavirus (MERS-CoV) was first identified in 2012 in Saudi Arabia among patients with severe respiratory disease. ${ }^{1}$ Since the first cases of MERS emerged, a wide spectrum of disease severity, ranging from asymptomatic infection to fatal pneumonia, has been documented among the confirmed MERS-CoV cases. $^{2,3}$ Initially, MERS-CoV predominantly affected middle-aged males; however, as the epidemic continued to spread, the gap between males and females has narrowed, and all age groups, from children to the elderly, have been affected. ${ }^{4-7}$ After an average incubation period of approximately 5 days, ${ }^{8}$ patients typically present with symptoms of lower respiratory tract infection, such as cough and shortness of breath often combined with nonspecific signs of the disease, such as fatigue, myalgia, fever, rhinorrhea, headaches, sore throat, vomiting, or diarrhea. ${ }^{9}$ In patients with pneumonia, MERS can rapidly 
progress to acute respiratory distress syndrome, acute renal failure, multi-organ failure, and death. ${ }^{9,10}$ Moreover, the presence of comorbidities such as diabetes, chronic kidney disease, and cardiovascular disease frequently leads to secondary complications, such as disseminated intravascular coagulation and hyperkalemia. ${ }^{11,12}$ On the other end of the spectrum, healthy immune-competent patients are more likely to have asymptomatic or mild infections which could have gone undetected and unreported. ${ }^{6,13}$

The MERS-CoV is a positive-strand RNA virus, which through cross species transmission infects both humans and animals. $^{14,15}$ The high propensity of MERS-CoV to cross species barriers is attributed to its ability to recombine and form new variants within the infected organism. ${ }^{16}$ This property of MERS-CoV, together with the lack of sufficient knowledge of the pathways by which the virus is transmitted to humans, is a matter of grave concern among virologists, public health researchers, and health activists. ${ }^{2,16}$ Despite a significant research effort in this area, the transmission of MERS-CoV is still puzzling many scientists and clinicians. ${ }^{17}$ One of the early hypotheses explaining the transmission of MERS-CoV from its natural host to humans raised the possibility that the virus may have originated in insectivorous bats. ${ }^{17}$ However, people do not commonly have contact with these species, particularly in the Arabian Peninsula where most cases have been reported. ${ }^{15,17,18}$ Conversely, human contacts with dromedary camels are commonplace in the Arabian Peninsula, especially in the regions with high reported incidence rates of MERS, suggesting that camels may be the source of human MERS-CoV infections. ${ }^{15,18,19}$ This possibility was supported by the detection of the MERS$\mathrm{CoV}$ in lymph nodes of camels in one of the slaughterhouses in Qatar; this finding suggested that MERS-CoV could be present in the camel meat. ${ }^{20}$ However, in an experiment involving infection of three camels with MERS-CoV, the virus was undetectable in their organs and the meat. ${ }^{21}$ Even if the camel meat is not associated with the transmission of the virus, almost two-thirds of the camels examined at a slaughterhouse in Qatar were shedding nasal excretion infected with MERS-CoV indicating the possibility of droplet transmission. ${ }^{20}$ In agreement with this finding, MERS$\mathrm{CoV}$ genomes were detected in nasal swabs collected from dromedaries in Oman, Saudi Arabia, Pakistan, Kuwait, Egypt, Iran, and Israel confirmed the presence of MERSCoV genomes. ${ }^{14}$ Several cases of infection in Saudi Arabia and Qatar have been linked to drinking raw camel milk. ${ }^{4,14}$ Given the potential causal relationship between the consumption of camel-derived food products and MERS, and the fact that the virus can be easily destroyed by pasteurization, ${ }^{14}$ the World Health Organization (WHO) advised against the consumption of raw camel milk and uncooked camel meat. ${ }^{20,21}$ Additionally, the WHO strongly discouraged drinking camel urine, which also could represent a risk factor for MERS-CoV infection. ${ }^{22,23}$

Although camels were implicated as the source of MERS-CoV transmission, the majority of the MERS patients did not come into close contact with camels or other livestock animals. ${ }^{24}$ Conversely, the vast majority of MERS cases have been associated with health care settings, ${ }^{24-26}$ with a particularly high risk of contracting the infection in overcrowded emergency rooms. ${ }^{27}$ In fact, most of the reported MERS-CoV cases in Saudi Arabia and South Korea were due to human-to-human transmission, which in most cases happened in the absence of adequate infection control measures in health care facilities. ${ }^{28,29}$ This mode of MERS-CoV transmission was confirmed both epidemiologically and by genetic documentation of the viruses implicated in hospital and household MERS outbreaks. ${ }^{16}$ Therefore, the importance of using the appropriate contact and droplet precautions in health care facilities cannot be overestimated. ${ }^{30}$

According to the WHO, from April 2012 to June 2019, 2,449 laboratory-confirmed cases of MERS were reported, of which 2,058 cases were in Saudi Arabia resulting in a casefatality rate of $37.2 \%{ }^{31}$ The incidence of MERS continues to rise, with seven new cases reported in June 2019 alone from Saudi Arabia. ${ }^{31}$ Overall, the majority of cases occurred in health care facilities, however, the routes of direct or indirect zoonotic transmission of MERS-CoV remain unknown. At present, no vaccine or specific treatment is available, although serious attempts to develop preventive therapy are ongoing. ${ }^{32}$ According to the World Bank, the Severe Acute Respiratory Syndrome coronavirus (SARS-CoV) outbreak resulted in an estimated global economic cost of $\$ 16$ billion, ${ }^{5}$ and it is believed that the MERS-CoV infection toll on the overall global economy, and particularly the Saudi economy, will also be enormous. The 2015 MERS-CoV outbreak in South Korea resulted in an estimated economic loss of $\$ 10$ billion in the tourism sector alone. ${ }^{33}$ Although among countries affected by MERS Saudi Arabia was impacted the most, no effort was made to estimate the immense impact of this epidemic on either the macro- or microeconomic levels. Therefore, the aim of the present study was to evaluate the direct medical costs associated with the management of MERS-CoV cases at one of the tertiary referral hospitals in Riyadh, Saudi Arabia. 


\section{Materials And Methods}

This was a retrospective chart review of confirmed cases of MERS-CoV in King Saud University Medical City, Riyadh, Saudi Arabia. The review covered all cases of MERS from January 2015 to October 2018. All confirmed cases of MERS-CoV that were diagnosed in the hospital or anywhere from the kingdom and were transferred to the hospital were collected. The collected data included sociodemographic characteristics (e.g., age, gender, marital status, nationality, employment in health care sector, and geographic region) as well as medical information (e.g., comorbidities, length of hospital stay, presenting symptoms, exposure to camels or their products or to a MERS case during the preceding 2 weeks, recent ( 2 weeks) hospitalization, and having H1N1 influenza prior to the admission).

Micro-costing was used to estimate the cost of hospitalization for each patient. These expenses were then used to calculate the mean cost for all of the confirmed MERS cases. The lowest, the highest, and the mean cost were used to project the direct medical cost of all MERS cases in the Kingdom. The information regarding items to be included in the cost analysis was retrieved from electronic medical records.

The expenses composed of the cost of personal protective equipment (e.g., N95 masks, gowns, protective eyewear), intravenous fluids and medications (e.g., antivirals, antibiotics, and other prescription medications), laboratory and diagnostic tests (e.g., CBC, liver and cardiac enzymes, swabs, cultures, chest $\mathrm{X}$-rays and CT scans), room fees (e.g., isolation rooms, intensive care unit, extended care rooms), and health care professionals (physicians and nurses) expenses based on the ministry of health hourly rates. The inpatient costs were obtained from the cost center at the Saudi Arabian Ministry of Health, and the medication costs were obtained from the online drug database of the Saudi Food and Drug Authority (SFDA). The costs in Saudi riyals were converted to US dollars using the exchange rate of $1 \mathrm{USD}=3.75 \mathrm{SAR}$.

The study was approved by the institutional review board of the College of Medicine at King Saud University, Riyadh, Saudi Arabia. The data are presented using descriptive statistics (mean, frequencies, and percentages). All analyses were conducted using the SAS statistical software (version 9.2, SAS Institute Inc., Cary, NC, USA).

\section{Results}

\section{Patients}

One hundred and forty-six patients reported to the hospital with symptoms consistent with MERS within the study period. In 44 of them, MERS-CoV was confirmed. However, a complete set of relevant information was available only for 24 patients (Figure 1). Sociodemographic characteristics of the patients are listed in Table 1. The majority of patients were female $(62.5 \%)$, and the mean age was $52.54 \pm 11.27$ years. More than half of the patients were married $(54.17 \%)$, and more than one-third of them were divorced $(37.50 \%)$. Saudi nationals constituted $62.50 \%$ of the study sample, and one-third of the patients were health care workers. Of the 24 MERS patients, 20 were from Riyadh, and one each from Al-Madinah, AlQaseem, Aseer, and Tabouk.

\section{Medical Characteristics Of MERS Patients}

The most frequent comorbidities among the patients were diabetes $(58.33 \%)$, hypertension $(37.50 \%)$, and chronic kidney disease (16.66\%) (Table 2). A few number of patients suffered from coronary artery disease, liver disease, asthma, peripheral vascular disease, and cancer. Fever $(50.00 \%)$, sore throat $(41.67 \%)$, chills $(41.67 \%)$, cough $(37.50 \%)$, and runny nose $(25.00 \%)$ were the most frequent presenting symptoms. Within the 2 weeks prior to hospital admission, one patient had contact with camels or their products, while $11(45.83 \%)$ were exposed to a MERS case (Table 2). Three patients $(12.5 \%)$ were hospitalized within the previous 2 weeks, two (8.33\%) had acute respiratory distress syndrome, and four had H1N1 influenza. The length of hospital stay varied significantly, ranging from 1 to 31 days, with a mean of $4.96 \pm 7.29$ days. Two of the 24 patients died, and 22 were discharged (Table 2).

All but six patients were admitted to the hospital due to flu-like symptoms (Table 3). The remaining six patients were admitted for septic arthritis, abdominal pain and dysuria, black discoloration of toes, bleeding during pregnancy, and hyponatremia, which are not typically associated with the MERS-CoV infection. Patients presenting with flu-like symptoms were diagnosed with MERS on the day of admission, while in the other instances the time from admission to the diagnosis of MERS varied from 1 day (abdominal pain and dysuria, bleeding during pregnancy) to 6 days (black discoloration of toes) as shown in Table 3. Notably, 14 patients $(58.3 \%)$ were discharged home within $24 \mathrm{hrs}$ of their diagnosis.

\section{Hospital Costs}

The cost of hospitalization for the 24 patients is detailed in Table 4. The total cost of managing a MERS case at the hospital ranged from $\$ 1278.41$ to $\$ 75,987.95$ with a mean 


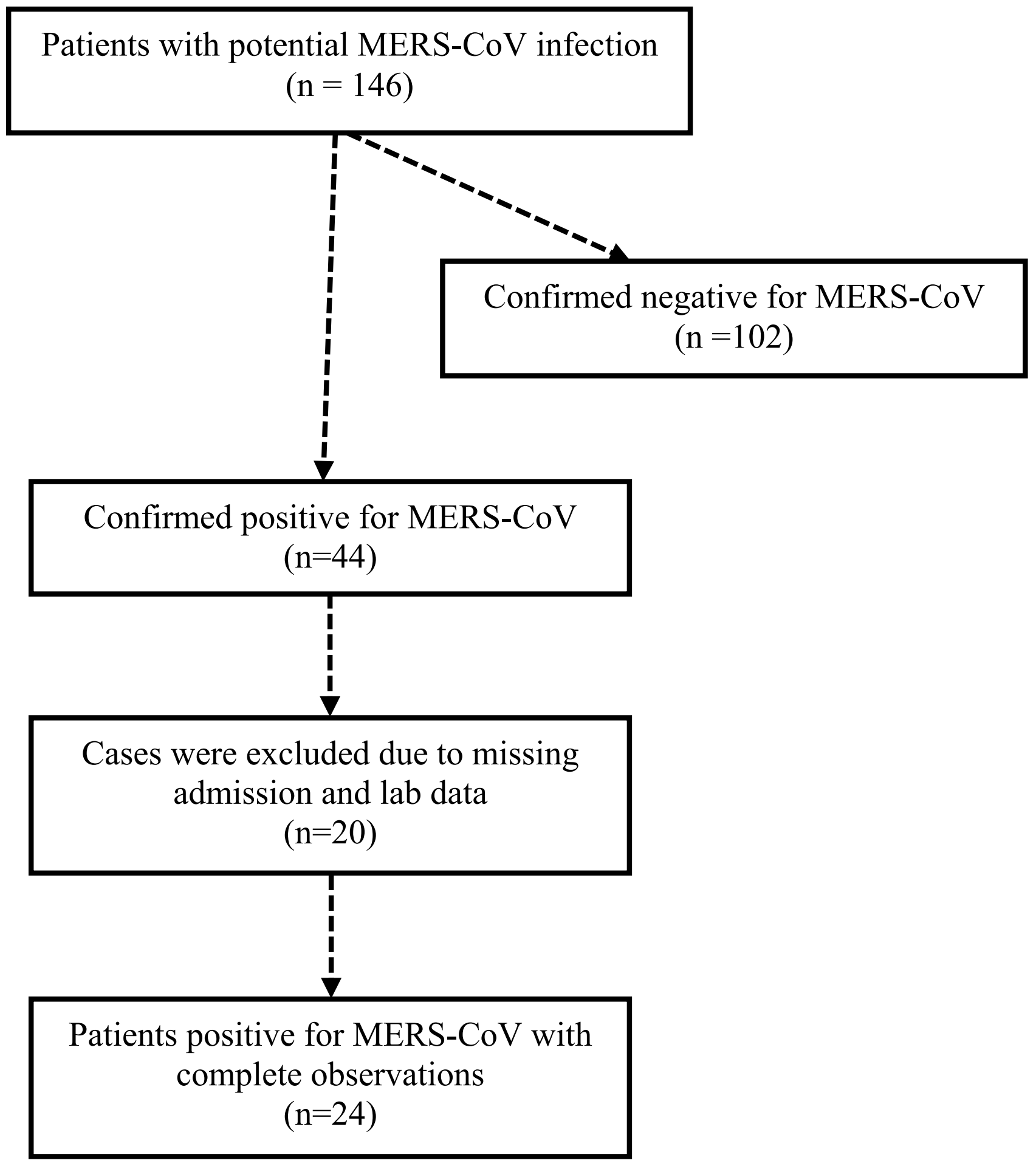

Figure I Patient recruitment scheme.

cost of $\$ 12,947.03 \pm 19,923.14$. The cost of care was under $\$ 20,000$ in $75 \%$ of the patients, therefore, the median cost, $\$ 1867.30$, was markedly lower than the mean, and the interquartile range was $\$ 2,839.03$. Eight cases had hospitalization costs higher than the mean cost
$(\$ 12,947.03)$, which was largely due to the longer length of stay (5-31 days vs 1-5 days). Moreover, the percentage of patients with diabetes ( $87.5 \%$ vs $43.75 \%$ ), hypertension $(75 \%$ vs $18.75 \%)$ as well as those on mechanical ventilation $(25 \%$ vs $0 \%)$, interferon and ribavirin $(25 \%$ vs $0 \%)$, 
Table I Sociodemographic Characteristics Of The Patients

\begin{tabular}{|c|c|}
\hline Characteristics & Patients $(\mathrm{N}=24)$ \\
\hline \multicolumn{2}{|l|}{ Gender } \\
\hline Male, n (\%) & $9(37.50)$ \\
\hline Female, n (\%) & $15(62.5)$ \\
\hline Age, years; mean $\pm S D$ & $52.54 \pm 11.27$ \\
\hline \multicolumn{2}{|l|}{ Marital status } \\
\hline Single, n (\%) & $2(8.33)$ \\
\hline Married, n (\%) & $13(54.17)$ \\
\hline Divorced, n (\%) & $9(37.50)$ \\
\hline \multicolumn{2}{|l|}{ Nationality } \\
\hline Saudi, n (\%) & $15(62.50)$ \\
\hline Non-Saudi, n (\%) & $9(37.50)$ \\
\hline \multicolumn{2}{|l|}{ Occupation } \\
\hline Health care worker, n (\%) & $8(33.33)$ \\
\hline Other, n (\%) & $16(66.67)$ \\
\hline \multicolumn{2}{|l|}{ Region } \\
\hline Riyadh, n (\%) & $20(83.33)$ \\
\hline Al-Madinah, n (\%) & I (4.16) \\
\hline Al-Qaseem, n (\%) & I (4.16) \\
\hline Aseer, n (\%) & I (4.16) \\
\hline Tabouk, n (\%) & I (4.16) \\
\hline
\end{tabular}

oseltamivir (50\% vs.6.25\%), and those with chronic kidney disease ( $37.5 \%$ vs $6.25 \%$ ), and cancer ( $25 \%$ vs $6.25 \%$ ) were higher among those cases compared to their counterparts with medical costs lower than the mean cost.

\section{Discussion}

Although some efforts in estimating the impact of MERSCoV outbreak on selected sectors of the economy in some countries like South Korea have been made, ${ }^{33}$ the direct medical costs of managing this epidemic that struck more than 24 countries and affected Saudi Arabia the most have not been estimated. The estimated costs of managing MERS cases in this study can be utilized to project the aggregate direct medical cost of managing MERS cases in Saudi Arabia. As of June 2019, 2058 cases of MERS were reported in the Kingdom. ${ }^{31}$ The cost of managing these patients at hospitals would range from \$2,630,967.78 (based on the lowest cost identified in the present analysis, i.e., $\$ 1278.41 \times 2058$ ) to $\$ 156,383,201.10$ (based on the highest cost, i.e., $\$ 75,987.95 \times 2058)$ with a mean cost of $\$ 26,644,987.74(\$ 12,947.03 \times 2058)$, and a median cost of $\$ 3,842,903.4(\$ 1867.30 \times 2,058)$.
Table 2 Medical Characteristics Of The Patients

\begin{tabular}{|c|c|}
\hline Characteristics & $\begin{array}{l}\text { Patients } \\
(\mathrm{N}=24)\end{array}$ \\
\hline \multicolumn{2}{|l|}{ Comorbidities } \\
\hline Coronary artery disease, $\mathrm{n}(\%)$ & I (4.16) \\
\hline Hypertension, n (\%) & $9(37.50)$ \\
\hline Diabetes, n (\%) & $14(58.33)$ \\
\hline Chronic kidney disease, $\mathrm{n}(\%)$ & $4(16.66)$ \\
\hline Liver disease, $\mathrm{n}(\%)$ & $2(8.33)$ \\
\hline Asthma, n (\%) & I (4.16) \\
\hline Peripheral vascular disease, $\mathrm{n}(\%)$ & I (4.16) \\
\hline Cancer, n (\%) & $3(12.50)$ \\
\hline \multicolumn{2}{|l|}{ Presenting symptoms } \\
\hline Fever, n (\%) & $12(50)$ \\
\hline Headache, n (\%) & $2(8.33)$ \\
\hline Cough, n (\%) & $9(37.50)$ \\
\hline Muscle aches, n (\%) & I (4.16) \\
\hline Difficulty breathing, n (\%) & $3(12.50)$ \\
\hline Runny nose, n (\%) & $6(25)$ \\
\hline Sore throat, n (\%) & $10(41.67)$ \\
\hline Weight loss, n (\%) & $2(8.33)$ \\
\hline Swelling, n (\%) & I (4.16) \\
\hline Pneumonia, n (\%) & I (4.16) \\
\hline Chills (shivering), n (\%) & $10(41.67)$ \\
\hline $\begin{array}{l}\text { Exposure to camels or their products within the past } \\
\text { two weeks, } n(\%)\end{array}$ & I (4.16) \\
\hline $\begin{array}{l}\text { Exposure to a MERS case within the past two weeks, } \\
\text { n (\%) }\end{array}$ & II (45.83) \\
\hline Prior hospitalization in the past two weeks, n (\%) & $3(12.5)$ \\
\hline Acute respiratory distress syndrome, $\mathrm{n}(\%)$ & $2(8.33)$ \\
\hline HINI influenza, n (\%) & $4(16.67)$ \\
\hline Length of stay, days; mean \pm SD & $4.96 \pm 7.29$ \\
\hline Died, n (\%) & $2(8.33)$ \\
\hline Discharged, n (\%) & $22(91.67)$ \\
\hline
\end{tabular}

These estimates include only the cost of inpatient MERS cases management and do not consider the costs associated with the implementation of infection control policies that were implemented right after the MERS-CoV outbreak, such as the cost of shutting down certain hospital wards. ${ }^{3}$ Moreover, it must be acknowledged that projected cost estimates in managing MERS cases in Saudi Arabia were based on expenses incurred for 24 MERS cases only and do not represent the diverse cases of MERS in the country. Despite these limitations, it should be emphasized that this is the first effort to highlight the direct medical cost of managing MERS cases in Saudi Arabia, a country where more than $80 \%$ of MERS cases were reported. ${ }^{31}$ 
Table 3 Reason For Admission And Time Of Diagnosis

\begin{tabular}{|c|c|c|c|c|}
\hline Patient & Reason For Admission & Date Of Diagnosis After Admission & Length Of Stay & Status \\
\hline I & Flu-like symptoms & Day I & 17 days & Died \\
\hline 2 & Flu-like symptoms & Day I & I day & Discharged \\
\hline 3 & Flu-like symptoms & Day I & I day & Discharged \\
\hline 4 & Flu-like symptoms & Day I & I day & Discharged \\
\hline 5 & Flu-like symptoms & Day I & I day & Discharged \\
\hline 6 & Septic arthritis & Day 3 & 15 days & Discharged \\
\hline 7 & Abdominal pain and dysuria & Day I & 2 days & Discharged \\
\hline 8 & Flu-like symptoms & Day I & I day & Discharged \\
\hline 9 & Black discoloration of toes & Day 6 & 10 days & Died \\
\hline 10 & Flu-like symptoms & Day I & I day & Discharged \\
\hline 11 & Flu-like symptoms & Day I & 2 days & Discharged \\
\hline 12 & Flu-like symptoms & Day I & I day & Discharged \\
\hline 13 & Flu-like symptoms & Day I & I day & Discharged \\
\hline 14 & Flu-like symptoms & Day I & I day & Discharged \\
\hline 15 & Came for a scheduled surgical procedure & Day 4 & 5 days & Discharged \\
\hline 16 & Flu-like symptoms & Day I & I day & Discharged \\
\hline 17 & Bleeding during pregnancy & Day I & I day & Discharged \\
\hline 18 & Hyponatremia & Day 3 & 8 days & Discharged \\
\hline 19 & Flu-like symptoms & Day I & I day & Discharged \\
\hline 20 & Flu-like symptoms & Day I & I day & Discharged \\
\hline 21 & Flu-like symptoms & Day I & I day & Discharged \\
\hline 22 & Flu-like symptoms & Day I & 10 days & Discharged \\
\hline 23 & Flu-like symptoms & Day I & 5 days & Discharged \\
\hline 24 & Flu-like symptoms & Day I & 31 days & Discharged \\
\hline
\end{tabular}

Most of the patients in the study sample had chronic health conditions, such as diabetes (58\%), hypertension (37\%), chronic kidney disease (17\%), and cancer (12\%). This is in agreement with the previously published studies which showed a significant relationship between multiple comorbidities and MERS-CoV infection. ${ }^{17}$ Moreover, the mean age of the patients was over 50 years which is also consistent with the notion that MERS-CoV rarely affects children and young adults. ${ }^{9}$ Notably, the low rate of mortality among the study sample (8.33\%) was significantly lower than the average mortality rate reported in the literature (35-40\%). ${ }^{9,31}$ This difference may be largely attributable to the small sample size and relatively short length of hospital stay of patients in the present investigation compared with previously published studies (Table 4).

The findings of this study underscore numerous issues and shortcomings within the Saudi health care system. Onethird of the patients included in the analysis were health care workers. The presence of such a high percentage of health professionals among MERS patients raises serious questions regarding the effectiveness and/or enforcement of infection control policies in hospitals. Moreover, it exposes the lack of response among decision makers to past calls for improvement, ${ }^{25,26}$ providing a grim outlook for the future. The inadequate prevention of nosocomial infections is further underlined by the fact that four of the 24 MERS cases $(16.67 \%)$ were admitted for symptoms that were not related to MERS infection, and the disease was identified three to 6 days later, suggesting that those patients caught the infection during their hospitalization, which questions again the effectiveness of the hospital infection control policy. Additionally, the unavailability of the data for 20 out of 44 MERS cases unveils poor documentation practices and lack of mandatory management protocols (Figure 1).

Although several studies have pointed to a strong association between the contact with camels and MERS-CoV infection, ${ }^{4,9,20}$ only one of the 24 MERS cases (4.17\%) reported an exposure to camels or their products, while 11 cases $(45.83 \%)$ reported being in contact with a MERS-CoV case within 2 weeks prior to their diagnosis with MERS. The high prevalence of MERS-CoV infections caused by humanto-human contact calls into question the effectiveness of infection control policies at the national level and reveals the inadequacy of the preventive measures taken by the Saudi Ministry of Health that persists after more than 3 years of the MERS-CoV outbreak. $^{25}$ In fact, the current analysis 


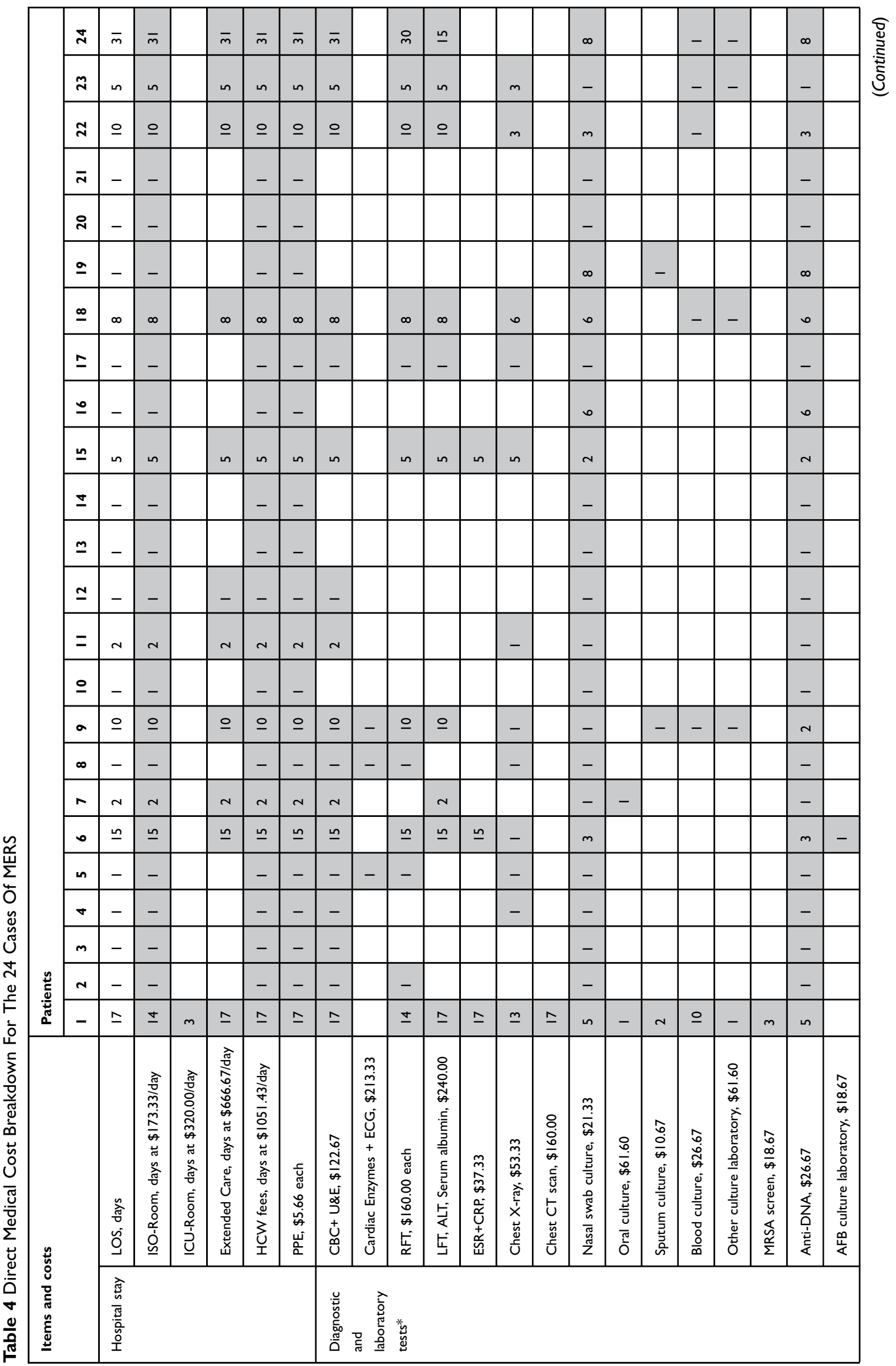




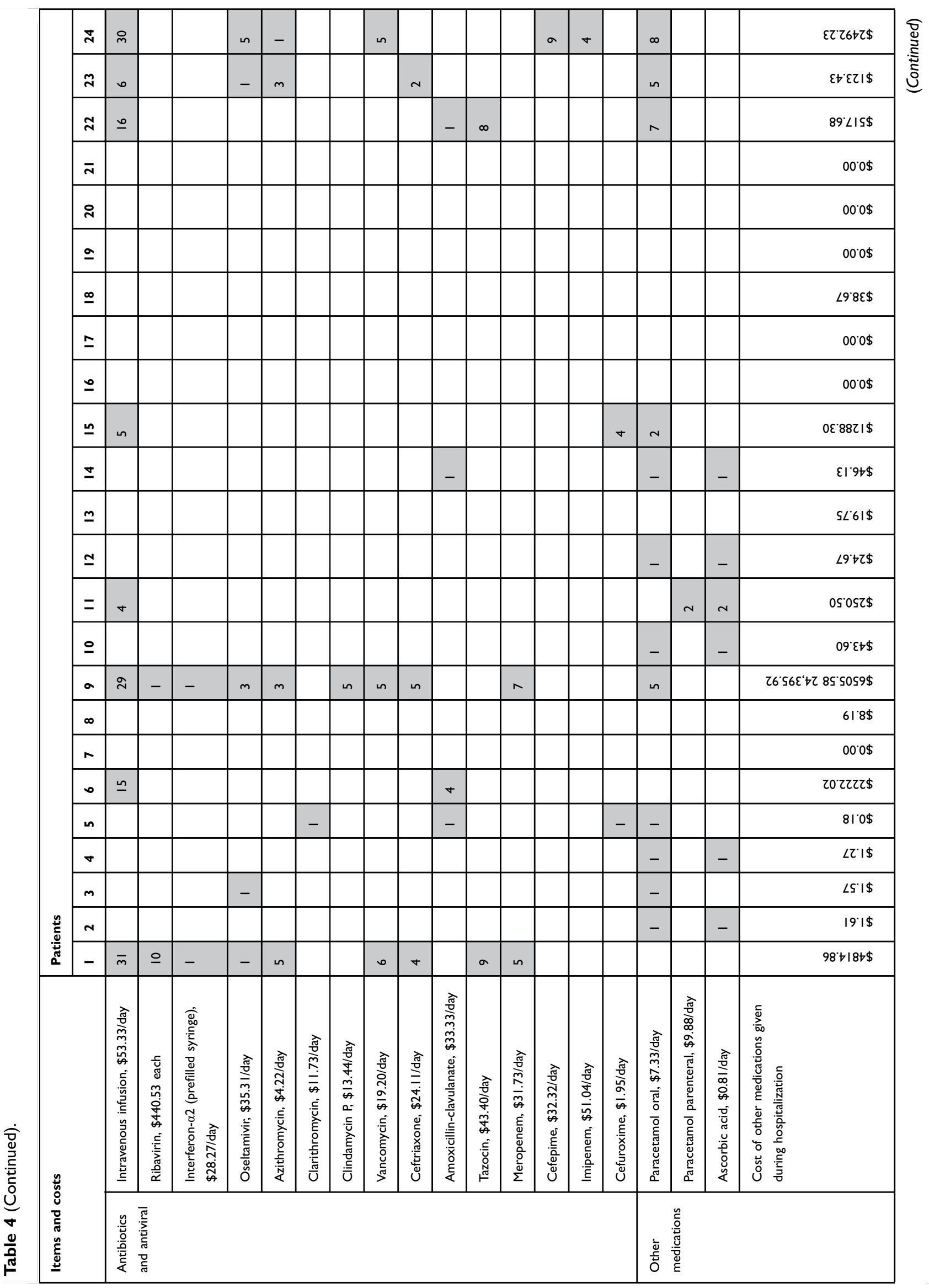




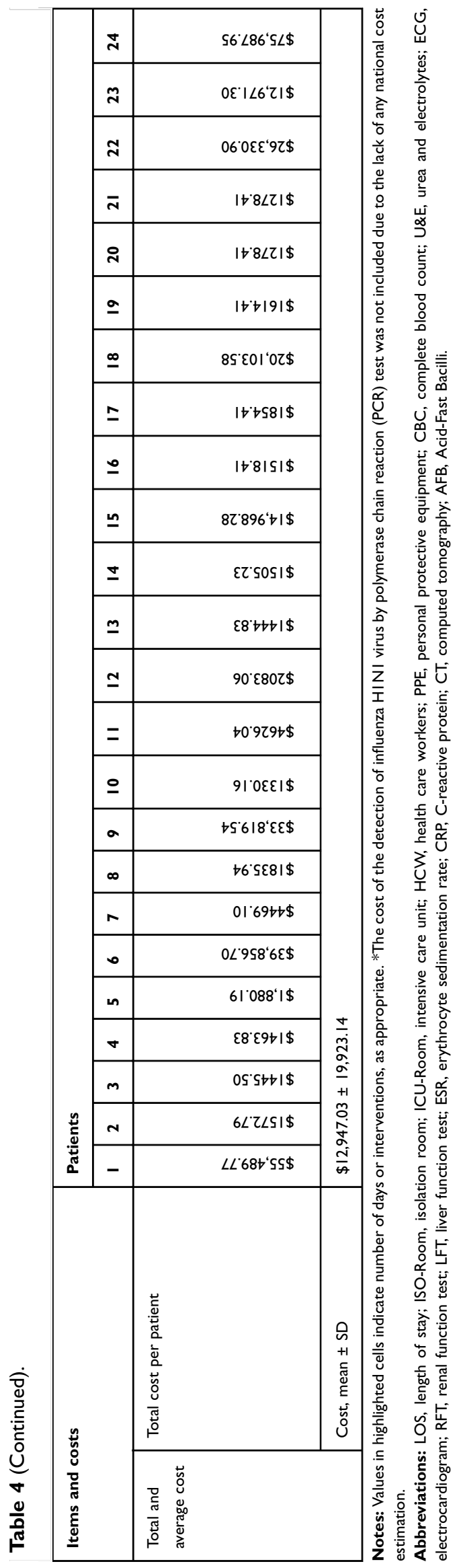

identified 13 cases (54\%) that were discharged within one day of their MERS diagnosis mainly due to the lack of available treatment and the fear of nosocomial transmission. However, the decision to discharge those patients could increase the risk of MERS-CoV transmission outside the hospital, particularly to those at higher risk, such as immunocompromised patients with diabetes and other health conditions prevalent in Saudi Arabia. ${ }^{34}$ This is concerning given that approximately $46 \%$ of the cases were exposed to a MERS case within the past 2 weeks prior to their admission. To control the transmission of MERS-CoV, patients diagnosed with MERS should have been quarantined, an intervention that was successfully implemented in South Korea to contain MERS-CoV outbreak in 2015. ${ }^{27,35}$ The failure to isolate sick patients contributes significantly to the perpetual problem in containing this epidemic that the Saudi health system is still grappling with. Lastly, as a part of the present investigation, a significant effort has been made to review more cases from multiple referral centers. However, these attempts went in vain. The lack of transparency in the management of MERS-CoV infections by some health care facilities in Saudi Arabia is alarming. Notably, the mismanagement of MERS epidemic in Saudi Arabia was highlighted in the press. ${ }^{36}$

\section{Conclusion}

The findings of this study highlight the enormous expenses incurred by the Saudi health system due to the MERS$\mathrm{CoV}$ outbreak. Although the accuracy of the direct medical cost estimation presented in this study is limited since it was merely a review of medical charts for 24 patients, an extensive effort was made to identify all relevant data about each eligible patient and capture every single cost item. To improve the accuracy of the current analysis on direct medical cost estimation for MERS patients, health researchers should be granted access to the medical files of all MERS cases. This may help in highlighting the deficiencies in the infection control policies. Finally, an enforceable nationwide policy for infection control, and standardized protocols for the management of MERS-CoV infections should be implemented.

\section{Abbreviations}

MERS-CoV, Middle East respiratory syndrome coronavirus; MERS, Middle East respiratory syndrome; SARS$\mathrm{CoV}$, severe acute respiratory syndrome coronavirus; WHO, World Health Organization; SFDA, Saudi Food and Drug Authority; USD, United States dollars. 


\section{Ethics Statement}

Ethical approval for this study was obtained from the institutional review board of the College of Medicine at King Saud University, Riyadh, Saudi Arabia (project number E-18-3008). No personal identifiers were collected and all data were coded to protect the confidentiality of the patients, in compliance with the Declaration of Helsinki. Furthermore, the need for written informed consent was waived, as per the institution policy, since the study was a retrospective chart review and did not involve any patient interviews.

\section{Data Sharing Statement}

Study data are available from the authors upon reasonable request.

\section{Acknowledgments}

The authors acknowledge financial support from the Researchers Supporting Project (number RSP-2019/16), King Saud University, Riyadh, Saudi Arabia. Also, the authors would like to thank Haya Al-Othaimeen, Mona Al-Salam, Somaya Alzahrani, and Prof. Edward De Vol for their data collection efforts.

\section{Author Contributions}

All authors contributed to data analysis, drafting or revising the article, gave final approval for the version to be published, and agree to be accountable for all aspects of the work.

\section{Disclosure}

The authors report no conflicts of interest in this work.

\section{References}

1. Zaki AM, van Boheemen S, Bestebroer TM, Osterhaus AD, Fouchier RA. Isolation of a novel coronavirus from a man with pneumonia in Saudi Arabia. N Engl J Med. 2012;367(19):1814-1820. doi:10.1056/ NEJMoa1211721

2. Cauchemez S, Nouvellet P, Cori A, et al. Unraveling the drivers of MERS-CoV transmission. Proc Natl Acad Sci U S A. 2016;113 (32):9081-9086. doi:10.1073/pnas.1519235113

3. Hajjar SA, Memish ZA, McIntosh K. Middle East Respiratory Syndrome Coronavirus (MERS-CoV): a perpetual challenge. Ann Saudi Med. 2013;33(5):427-436. doi:10.5144/0256-4947.2013.427

4. Memish ZA, Cotten M, Meyer B, et al. Human infection with MERS coronavirus after exposure to infected camels, Saudi Arabia, 2013. Emerg Infect Dis. 2014;20(6):1012-1015. doi:10.3201/eid2006.140 402

5. Milne-Price S, Miazgowicz KL, Munster VJ. The emergence of the Middle East respiratory syndrome coronavirus. Pathog Dis. 2014;71 (2):121-136. doi:10.1111/2049-632X.12166
6. Ki M. 2015 MERS outbreak in Korea: hospital-to-hospital transmission. Epidemiol Health. 2015;37:e2015033-e33. doi:10.4178/epih/ e2015033

7. Bin SY, Heo JY, Song MS, et al. Environmental contamination and viral shedding in MERS patients during MERS-CoV outbreak in South Korea. Clin Infect Dis. 2016;62(6):755-760. doi:10.1093/cid/ civ 1020

8. Virlogeux V, Fang VJ, Wu JT, et al. Incubation period duration and severity of clinical disease following severe acute respiratory syndrome coronavirus infection. Epidemiology. 2015;26:666-669. doi:10.1097/EDE.0000000000000339

9. Mackay IM, Arden KE. MERS coronavirus: diagnostics, epidemiology and transmission. Virol J. 2015;12(1):222. doi:10.1186/s12985015-0439-5

10. Al-Hameed F, Wahla AS, Siddiqui S, et al. Characteristics and outcomes of Middle East respiratory syndrome coronavirus patients admitted to an intensive care unit in Jeddah, Saudi Arabia. $J$ Intensive Care Med. 2016;31(5):344-348. doi:10.1177/08850666155 79858

11. Alraddadi BM, Watson JT, Almarashi A, et al. Risk factors for primary Middle East respiratory syndrome coronavirus illness in humans, Saudi Arabia, 2014. Emerg Infect Dis. 2016;22(1):49-55. doi:10.3201/eid2201.151340

12. Thabet F, Chehab M, Bafaqih H, Al Mohaimeed S. Middle East respiratory syndrome coronavirus in children. Saudi Med J. 2015;36 (4):484-486. doi:10.15537/smj.2015.4.10243

13. Kim KH, Tandi TE, Choi JW, Moon JM, Kim MS. Middle East respiratory syndrome coronavirus (MERS-CoV) outbreak in South Korea, 2015: epidemiology, characteristics and public health implications. J Hosp Infect. 2017;95(2):207-213. doi:10.1016/j.jhin.2016.10. 008

14. Reusken C, Haagmans BL, Koopmans MP. [Dromedary camels and Middle East respiratory syndrome: MERS coronavirus in the 'ship of the desert']. Ned Tijdschr Geneeskd. 2014;158:A7806.

15. Baseler L, de Wit E, Feldmann H, Comparative A. Review of animal models of Middle East respiratory syndrome coronavirus infection. Vet Pathol. 2016;53(3):521-531. doi:10.1177/0300985815620845

16. Zumla A, Hui DS, Perlman S. Middle East respiratory syndrome. Lancet. 2015;386(9997):995-1007. doi:10.1016/S0140-6736(15)60454-8

17. Shehata MM, Gomaa MR, Ali MA, Kayali G. Middle East respiratory syndrome coronavirus: a comprehensive review. Front Med. 2016;10(2):120-136. doi:10.1007/s11684-016-0430-6

18. Chan JF, Lau SK, To KK, et al. Middle East respiratory syndrome coronavirus: another zoonotic betacoronavirus causing SARS-like disease. Clin Microbiol Rev. 2015;28(2):465-522. doi:10.1128/CMR.0010214

19. Hemida MG, Chu DK, Poon LL, et al. MERS coronavirus in dromedary camel herd, Saudi Arabia. Emerg Infect Dis. 2014;20 (7):1231-1234. doi:10.3201/eid2007.140571

20. Farag EA, Reusken CB, Haagmans BL, et al. High proportion of MERS-CoV shedding dromedaries at slaughterhouse with a potential epidemiological link to human cases, Qatar 2014. Infect Ecol Epidemiol. 2015;5:28305.

21. Adney DR, Brown VR, van Doremalen N, et al. Efficient replication and shedding of MERS CoV from the upper respiratory tract of experimentally infected dromedary camels. New Horiz Transl Med. 2015;2(4):131.

22. Aburizaiza AS, Mattes FM, Azhar EI, et al. Investigation of antimiddle East respiratory syndrome antibodies in blood donors and slaughterhouse workers in Jeddah and Makkah, Saudi Arabia, fall 2012. J Infect Dis. 2014;209(2):243-246. doi:10.1093/infdis/jit589

23. Gossner C, Danielson N, Gervelmeyer A, et al. Human-dromedary camel interactions and the risk of acquiring zoonotic Middle East respiratory syndrome coronavirus infection. Zoonoses Public Health. 2016;63(1):1-9. doi:10.1111/zph.2016.63.issue-1 
24. Widagdo W, Raj VS, Schipper D, et al. Differential expression of the Middle East respiratory syndrome coronavirus receptor in the upper respiratory tracts of humans and dromedary camels. J Virol. 2016;90 (9):4838-4842. doi:10.1128/JVI.02994-15

25. Balkhy HH, Perl TM, Arabi YM. Preventing healthcare-associated transmission of the Middle East Respiratory Syndrome (MERS): our Achilles heel. J Infect Public Health. 2016;9(3):208-212. doi:10.1016/j. jiph.2016.04.006

26. Almutairi AF, Adlan AA, Balkhy HH, Abbas OA, Clark AM. "It feels like I'm the dirtiest person in the world": exploring the experiences of healthcare providers who survived MERS-CoV in Saudi Arabia. J Infect Public Health. 2018;11(2):187-191. doi:10.1016/j.jiph.2017.06.011

27. Cho SY, Kang JM, Ha YE, et al. MERS-CoV outbreak following a single patient exposure in an emergency room in South Korea: an epidemiological outbreak study. Lancet. 2016;388(10048):994-1001. doi:10.1016/S0140-6736(16)30623-7

28. Korea Centers for Disease Control and Prevention. Middle East respiratory syndrome coronavirus outbreak in the Republic of Korea, 2015. Osong Public Health Res Perspect. 2015;6:269-278. doi:10.1016/j.phrp.2015.08.006

29. World Health Organization. Middle East respiratory syndrome coronavirus (MERS-CoV): summary of current situation, literature update and risk assessment - as of 5 February, 2015. 2015. https:// www.who.int/csr/disease/coronavirus_infections/mers-5-february2015.pdf. Accessed August 10, 2019.
30. Hui DS, Azhar EI, Kim YJ, Memish ZA, Oh MD, Zumla A. Middle East respiratory syndrome coronavirus: risk factors and determinants of primary, household, and nosocomial transmission. Lancet Infect Dis. 2018;18:e217-e227. doi:10.1016/S1473-3099(18)30127-0

31. World Health Organization. MERS situation update. June 2019. http://www.emro.who.int/health-topics/mers-cov/mers-outbreaks. html. Accessed August 10, 2019.

32. Zhou Y, Jiang S, Du L. Prospects for a MERS-CoV spike vaccine. Expert Rev Vaccines. 2018;17(8):677-686. doi:10.1080/14760584.2018.15067 02

33. Joo H, Maskery BA, Berro AD, Rotz LD, Lee YK, Brown CM. Economic impact of the 2015 MERS outbreak on the Republic of Korea's tourism-related industries. Health Secur. 2019;17:100-108. doi:10.1089/hs.2018.0115

34. Naeem Z. Burden of diabetes mellitus in Saudi Arabia. Int J Health Sci (Qassim). 2015;9(3):V-VI.

35. Lee SI. Costly lessons from the 2015 Middle East respiratory syndrome coronavirus outbreak in Korea. J Prev Med Public Health. 2015;48:274-276. doi:10.3961/jpmph.15.064

36. McDowall A, Kelland K Saudi MERS response hobbled by institutional failings. 2014. https://www.reuters.com/article/us-saudi-mersfailings-insight/saudi-mers-response-hobbled-by-institutional-fail ings-idUSKBN0EN1I520140612. Accessed August 10, 2019.
Infection and Drug Resistance

\section{Publish your work in this journal}

Infection and Drug Resistance is an international, peer-reviewed openaccess journal that focuses on the optimal treatment of infection (bacterial, fungal and viral) and the development and institution of preventive strategies to minimize the development and spread of resistance. The journal is specifically concerned with the epidemiology of antibiotic resistance and the mechanisms of resistance development and diffusion in both hospitals and the community. The manuscript management system is completely online and includes a very quick and fair peerreview system, which is all easy to use. Visit http://www.dovepress.com/ testimonials.php to read real quotes from published authors. 